\title{
Presumed Intraocular Tuberculosis: An Unusual Presentation
}

\author{
Rajiv Garg*, Siddharth Madan, Maansi Sethi and Sarita Beri \\ Department of Ophthalmology, Lady Hardinge Medical College, India
}

Submission: November 14, 2017; Published: December 05, 2017

*Corresponding author: Rajiv Garg, Director Professor of Ophthalmology and Director, Lady Hardinge Medical College \& Associated Hospitals, University of Delhi, New Delhi-110001, India, Tel: +919811505854/+9101123408308; Email: rajivgarg58@gmail.com

\begin{abstract}
Background: The pathogenesis, variable clinical presentations and diagnostic accountability of various forms of intraocular tuberculosis, especially that involving posterior segment, have been a subject of extensive discussion and debated for long.

Methods: We report a 23 year male who presented with acute onset diminution of vision in his right eye. On comprehensive evaluation, he had bilateral disseminated multifocal choroiditis of presumed tubercular origin with an unusual presentation in the form of active papillophlebitis and pre-retinal hemorrhage in the right eye.
\end{abstract}

Results and conclusion: Remarkable response to treatment highlights common underlying pathogenesis for this unusual manifestation of intraocular tuberculosis.

Keywords: Intraocular Tuberculosis; Multifocal disseminated Choroiditis; Papillophlebitis

\section{Introduction}

Guidelines for diagnosis of intraocular tuberculosis (TB) in either immunocompetent or immunocompromised individuals are non-uniform. Tubercular choroiditis is responsible for approximately $37 \%$ cases of posterior uveitis in a TB endemic country like India, where the prevalence is estimated to be 2.5 million and 2.2 million cases out of a global incidence of 9.6 million exist as per World Health Organisation TB statistics [1]. If diagnosed early, it is a readily curable disease; a delayed ocular or systemic diagnosis can portend a poor prognosis for the patient.

\section{Case Report}

A 23-year-old, lean and slightly underweight mobile repair shop worker presented with acute onset progressive blurring of vision in right eye (Oculus dexter, OD) for 15 days, being more pronounced for last 3 days. A solitary tiny non progressive cobweb-like floater was noticed OD ten days back, more appreciable against light background. At presentation, unaided visual acuity OD was 6/36 without any improvement with pin hole or refractive correction; left eye (Oculus sinister, OS) Best Corrected Visual Acuity (BCVA) was 6/6 (partial) that improved from $6 / 18$ with a -0.50 dipoters of spherical correction. There were no accompanying ocular or systemic co-morbidities. Patient's mother was treated for tubercular cervical lymphadenopathy twenty years back with a 6-month course of anti-tubercular treatment (ATT). General physical and systemic examination was unremarkable except for the absence of Bacillus Calmette Guerin (BCG) immunization scar mark. Anterior segment evaluation and pupils were normal. Dilated funduscopy in right eye (Figure 1a) demonstrated a clear media, a hyperemic disc with blurred margins and obliterated cup with a large pre-retinal hemorrhage around the optic disc suggestive of papillophlebitis. Background retina had multiple ill-defined yellow-white lesions that measured less than one third of optic disc diameter, in all four quadrants involving the macula alongwith a dull foveal reflex pointing to disseminated multifocal choroiditis. Similar lesions were less pronounced in the left eye (Figure 1b), however, the optic disc and macula were normal. Venous pulsations were appreciable without any vascular tortuosity. Intraocular pressure was $10 \mathrm{mmHg}$ OD and $14 \mathrm{mmHg}$ OS. Visual field testing revealed a generalized reduction in sensitivity in both eyes. Color vision and Amsler grid test were normal in both eyes. Fundus fluorescein angiography was performed that revealed early hypo-fluorescence (Figure 1c \& 1d) followed by late hyper-fluorescence on the margins of the lesion (suggestive of active choroiditis-Figure 1e \& 1f) alongwith late disc leakage suggestive of papillophlebitis. Papillitis was ruled out in view of near normal visual fields and color vision. Complete hemogram, erythrocyte sedimentation rate, coagulation profile were normal. However, standard mantoux 


\section{Juniper Online Journal of Case Studies}

test with 5Tuberculin units was strongly positive with an induration of $23 \times 23 \mathrm{~mm}$. Serological investigations for syphilis, toxoplasmosis, rubella, CMV, herpes, sarcoidosis, systemic lupus erythematosus and human immune deficiency virus were negative. Ultrasound abdomen, chest X ray, contrast enhanced computed tomography of the chest and abdomen, all were within normal limits.

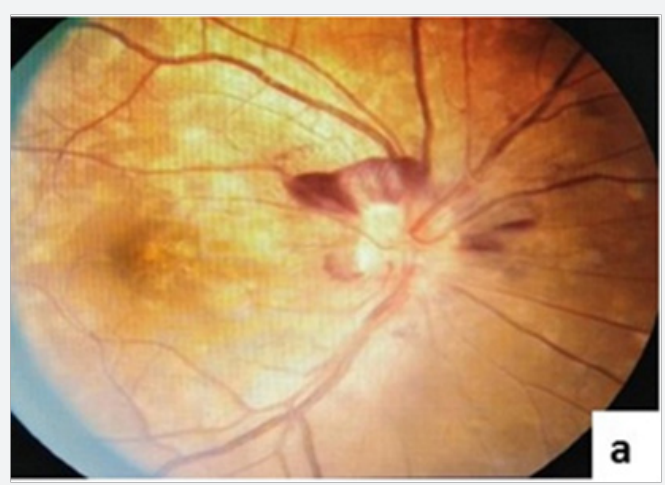

Figure 1a: Fundus photographs of the right eye (a) demonstrating a hyperemic disc with blurred margins and a obliterated cup, large pre-retinal hemorrhage around the optic disc along-with multiple ill-defined yellow-white lesions in all four 4 quadrants.

In the background of absent BCG scar mark, a strongly positive mantoux test and residence of this patient in a TB endemic area, a course of ATT consisting of isoniazid (300 mg), rifampicin (600mg), pyrazinamide (1600mg) and ethambutol (1100mg) daily was initiated along-with concomitant oral prednisolone in a dose of $1 \mathrm{mg} / \mathrm{kg}$ body weight in view of presumed tubercular multifocal disseminated choroiditis. Steroids were gradually tapered over four weeks. Peripheral choroid tubercles healed partially with a well demarcated and pigmented chorioretinal scar one week later with a BCVA of 6/90D and 6/60S. Preretinal haemorrhage and disc swelling started resolving as well (Figure $1 \mathrm{~g} \& 1 \mathrm{~h}$ ). There was no recurrence of inflammation after

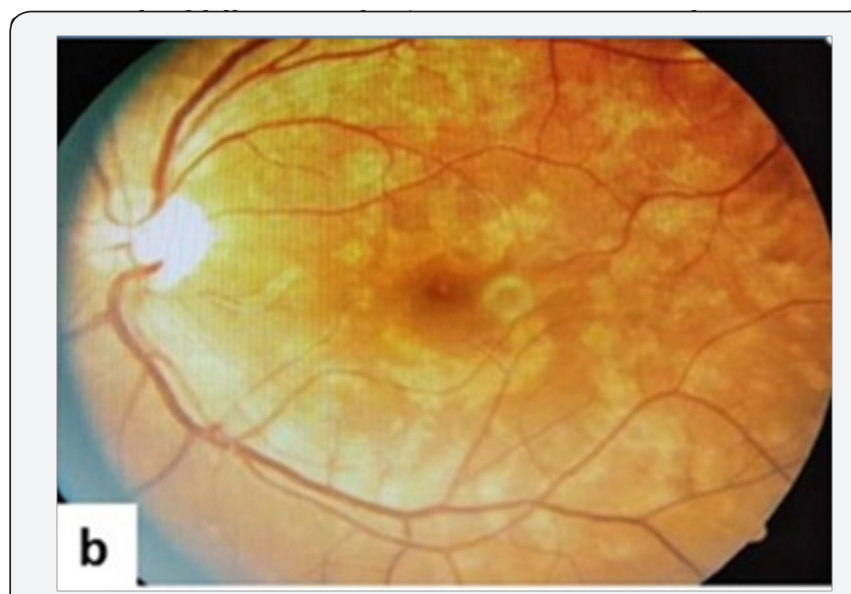

Figure 1b: Fundus photographs of the Left eye (b) also had similar findings but the optic disc was normal.
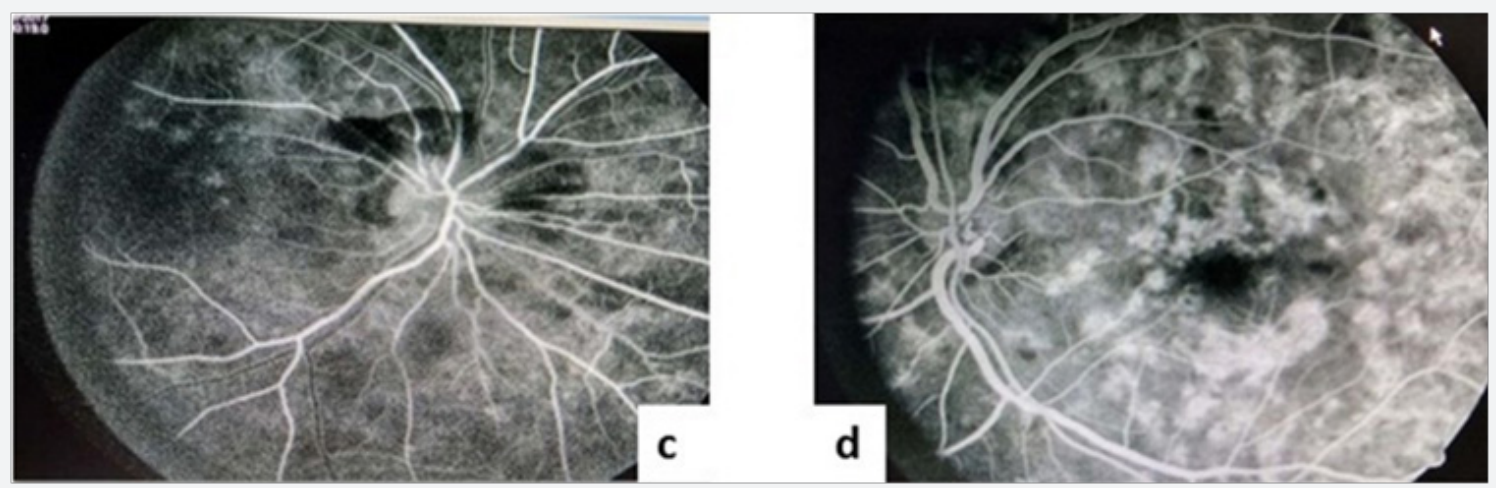

Figure 1c \& 1d: On performing a fundus fluorescein angiography, areas of early hypo-fluorescence (c, d) were seen.
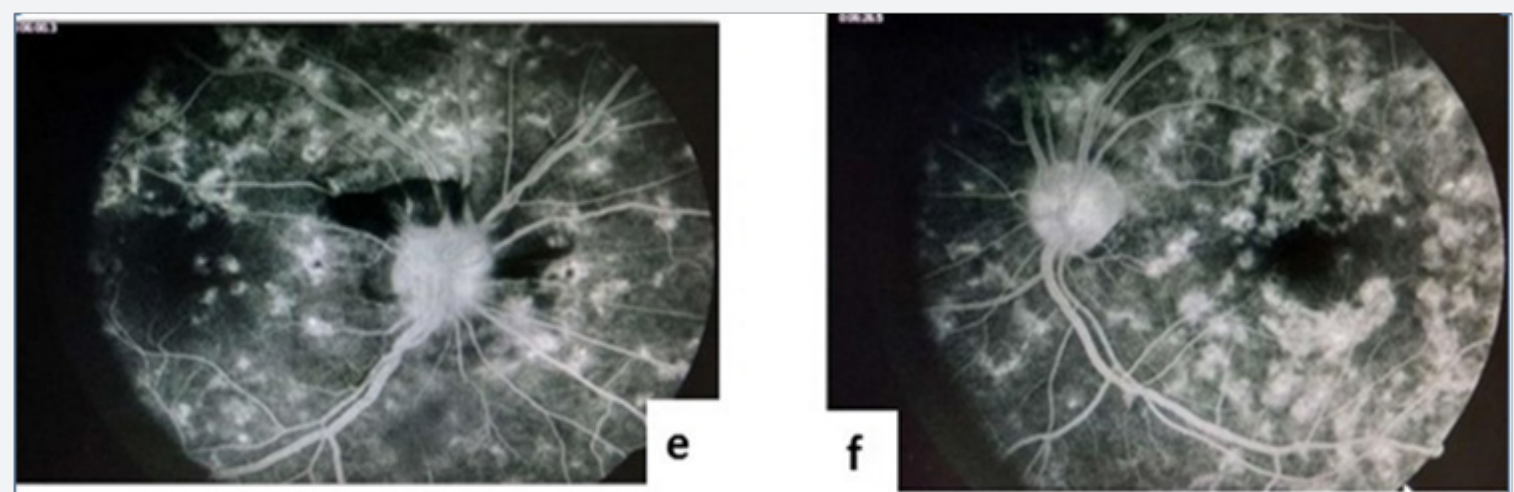

Figure 1e \& 1f: Late hyper-fluorescence $(e, f)$ was seen on the margins of the lesion accompanied with late disc leakage, features consistent with papillophlebitis with disseminated multifocal choroiditis. 

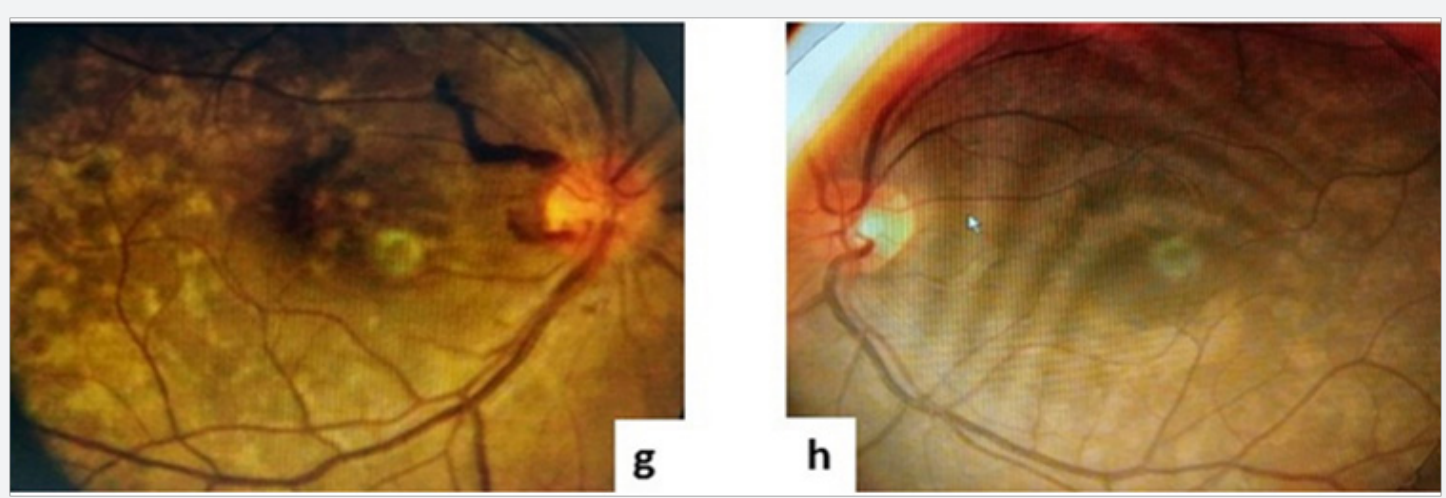

Figure 1g \& 1h: After initiation of treatment, pre-retinal haemorrhages, optic disc swelling started to resolve (g,h) and choroid tubercles were observed to heal partially with easily discernable chorioretinal scarring accompanied by pigment proliferation.

\section{Discussion}

This patient was diagnosed with presumed tuberculosis as per the criteria defined by Gupta et al. [2], which includes presence of choroidal involvement (out of the suggested clinical signs), a strongly positive mantoux reaction with a definitive response to ATT over a period of 4-6 weeks. Also, the diagnosis of presumed tubercular uveitis is supported by the presence of a hyper positive tuberculin skin test with uveitis and the exclusion of other possible etiologies as suggested by Cimino et al. TB-associated uveitis needs a high index of suspicion for diagnosis. Socioeconomic circumstances, family history and ethnic origin of the patient are important clues leading to consideration of tubercular etiology in patients with unexplained posterior uveitis. In the absence of clinical indicators, timely administration of ATT in the patients with presumed intraocular tuberculosis may significantly reduce the number of recurrences and a positive response to treatment constitute an essential diagnostic criteria [3]. Papillophlebitis is a rare manifestation of TB in patients with uveitis and optic nerve involvement [4]. Prompt diagnosis and initiation of ATT combined with systemic corticosteroids improves visual functions and leads to resolution of inflammation without recurrences [5].

\section{References}

1. Das D, Bhattacharjee H, Das K, Tahiliani PS, Bhattacharyya $\mathrm{P}$, et al. (2015) The changing patterns of uveitis in a tertiary institute of Northeast India. Indian J Ophthalmol 63(9): 735-737.

2. Gupta A, Sharma A, Bansal R, Sharma K (2015) Classification of intraocular tuberculosis. Ocul Immunol Inflamm 23(1): 7-13.

3. Parchand S, Tandan M, Gupta V, Gupta A (2011) Intermediate uveitis in Indian population. J Ophthalmic Inflamm Infect 1(2): 65-70.

4. Chawla H, Vohra V, Malik P (2016) Optic neuritis with secondary retinal venous stasis in a case of abdominal tuberculosis. Oman J Ophthalmol 9(3): 182-184.

5. Abu El Asrar AM, Al Mezaine HS (2010) Anti-tuberculous therapy combined with systemic corticosteroids improves retinal sensitivity in patients with active presumed tuberculous choroiditis. Int Ophthalmol 30(5): 567-576.

Your next submission with Juniper Publishers
will reach you the below assets
- Quality Editorial service
- Swift Peer Review
- Reprints availability
- E-prints Service
- Manuscript Podcast for convenient understanding
- Global attainment for your research
- Manuscript accessibility in different formats
( Pdf, E-pub, Full Text, Audio)
- Unceasing customer service
Track the below URL for one-step submission
https://juniperpublishers.com/online-submission.php

